\title{
REVISÃO NARRATIVA SOBRE AS PRÁXIS DA EDUCAÇÃO EM SAÚDE: POR UMA EDUCAÇÃO CONTEXTUALIZADA
}

\author{
Telma Temoteo dos Santos ${ }^{1}$ \\ Rosane Moreira Silva de Meirelles ${ }^{2}$
}

\begin{abstract}
RESUMO: A educação em saúde é dependente da estrita conexão entre os saberes científicos e comuns e o cotidiano/vivências dos indivíduos participantes, de modo a produzir resultados capazes de mudar a situação de vida. Assim, este trabalho conduziu uma revisão narrativa sobre a contextualização das práticas dos profissionais da educação e saúde por meio dos temas geradores freirianos buscando convergências com pesquisas que se debruçaram sobre os desafios no enfrentamento de agravos à saúde. Para isso, buscou-se a sustentação teórica e epistemológica em autores da Pedagogia Crítica e Popular que defendem uma prática dialógica oriunda do contexto dos sujeitos. Apontamos que é plausível a introdução dos temas geradores nas práxis da educação em saúde e que as reflexões iniciais podem levar ao desenvolvimento de trabalhos contextualizados para a educação e saúde.
\end{abstract}

Palavras-chave: Educação em saúde. Temas Geradores. Paulo Freire.

\section{NARRATIVE REVIEW ON THE PRAXIS OF HEALTH EDUCATION: FOR A CONTEXTUALIZED EDUCATION}

ABSTRACT: Health education is dependent on the strict connection between scientific and common knowledge and the daily life / experiences of the participating individuals, in order to produce results capable of changing the life situation. Thus, this work conducted a narrative review on the contextualization of the practices of education and health professionals through the generating Freire themes, seeking convergences with research that addressed the challenges in facing health problems. For that, we sought the theoretical and epistemological support in authors of Critical and Popular Pedagogy who defend a dialogical

\footnotetext{
${ }^{1}$ Doutora e Mestre em Ciências (Ensino de Biociências e Saúde) pelo Instituto Oswaldo Cruz (IOC/FIOCRUZ). Graduada em Ciências Biológicas (modalidade Licenciatura) pela Universidade do Estado do Rio de Janeiro (UERJ) e em Pedagogia, pela Universidade Nove de Julho (UNINOVE). Docente substituta (Biologia) no Instituto Federal do Norte de Minas Gerais (IFNMG), campus Salinas, em cursos de graduação e no ensino médio técnico.

2 Doutora e Mestre em Ciências pelo Programa de Biologia Celular e Molecular do Instituto Oswaldo Cruz (IOCFiocruz). Professora Adjunta no Departamento de Ensino de Ciências e Biologia (DECB - IBRAG - UERJ), desde 2015.
} 
practice originating from the context of the subjects. We point out that it is plausible to introduce generating themes in the praxis of health education and that the initial reflections can lead to the development of contextualized works for education and health.

Keywords: Health education. Generating Themes. Paulo Freire.

\title{
REVISIÓN NARRATIVA SOBRE LA PRAXIS DE LA EDUCACIÓN SANITARIA: PARA UNA EDUCACIÓN CONTEXTUALIZADA
}

\begin{abstract}
RESUMEN: El la educación sanitaria depende de la conexión estricta entre el conocimiento científico y común y la vida diaria / experiencias de los individuos participantes, con el fin de producir resultados capaces de cambiar la situación de la vida. Por lo tanto, este trabajo realizó una revisión narrativa sobre la contextualización de las prácticas de los profesionales de la educación y la salud a través de la generación de temas de Freire, buscando convergencias con investigaciones que aborden los desafíos para enfrentar los problemas de salud. Para ello, buscamos el apoyo teórico y epistemológico en autores de Pedagogía Crítica y Popular que defienden una práctica dialógica originada en el contexto de los sujetos. Señalamos que es plausible introducir temas generadores en la práctica de la educación para la salud y que las reflexiones iniciales pueden conducir al desarrollo de trabajos contextualizados para la educación y la salud.
\end{abstract}

Palabras clave: Educación en salud.Temas Generadores. Paulo Freire.

\section{Introdução}

O químico llya Prigogine, em sua Carta as futuras gerações, faz reflexões sobre a (re)modulação das sociedades dos pós-guerras e das revoluções políticas, econômicas e tecnológicas. Questiona quais desafios irão imperar na nova era das incertezas e conclama uma reforma que conduza a reconciliação das ciências naturais e humanas e ao respeito da biodiversidade de pensamentos (PRIGOGINE, 2009; 2003).

Entretanto, a aprendizagem instituída em grande parte das escolas tem fins propedêuticos sendo denunciado, desde meados do século passado, como as investidas do mercado global e capital sobre as escolas têm modulado o ensino. A educação deixa de ser considerada preceito para exercício da cidadania, instrumento para universalização dos direitos sociais, para um bem negociável, submissa a uma 
transvestida Reforma de Estado (BRANDÃO, 2012; FONSECA, 1998; BRASIL, 1988). Recebe a alcunha de mercadoria e passa a ter seus elementos mediadores (livros didáticos, softwares educativos, materiais escolares e, até mesmo, a formação inicial e continuada de professores) como negociáveis; sendo lógico concluir que os objetivos da educação passaram a atender, prioritariamente, os anseios de quem nela investe e negocia, levando a ampliação dos conglomerados de instituições privadas (que estendem o controle para o âmbito público) enquanto as necessidades dos indivíduos e de seus contextos são ignorados (GIROUX; SIMON, 2011; OLIVEIRA, 2009; CHAUÍ, 2003; SILVA, 2002).

Aos moldes de um sistema neoliberal enseja-se um ensino voltado para a transferência de conteúdos, sendo o número de acessos/pessoas alcançadas suficiente para ratificar a ocorrência de democratização do saber. São preceitos de uma sociedade que primazia a informação (o quantitativo sobre o qualitativo) no lugar do conhecimento, apesar de ser do último que ela necessita para alavancar mudanças em áreas estratégicas, como a contenção de doenças, a recuperação de áreas degradadas, a obtenção de fontes de energia limpa e mais eficientes, a formulação das novas tecnologias, o entendimento e a preservação dos povos, histórias e culturas e a transformação das formas de ensino, educação e escolas (MINAYO, 2011; LARRETA, 2003).

Em paralelo, os profissionais das áreas de Educação e Ensino submergem em pesquisas sobre o quê, como e para quem ensinar, conclamados em prover respostas a problemáticas que vão além do processo de formação acadêmica. Essas questões trazem à tona, no primeiro lugar, sobre os entraves da escola em ofertar uma educação que consiga transpor problemas globais para realidades locais e vice-versa. Um dos pontos é o modelo de formação engessada dos professores, priorizando os aspectos técnicos sem teorizações suficientes sobre a prática docente (CHARLOT, 2013; FRANCO, 2012; PIMENTA, 1999). Desse modo, o abismo entre academia, escola e sociedade se aprofunda, ora com os seus respectivos atores sociais eximindo-se das responsabilidades e/ou sem as melhores condições de executar de forma isolada as tarefas sociais impostas (ROLDÃO, 2001; PORLÁN; RIVERO,1998).

Para Streck (2012), a educação, apesar de estar longe de conseguir elucidar todas as atribuições que lhe são apresentadas, possui papel político e, por isso, não 
pode furtar-se de sensibilizar os indivíduos para as complexas questões da sociedade moderna. Espera-se que o espaço escolar não reitere as desigualdades já consubstanciadas na sociedade, não as fomentem com práticas excludentes, obtendo êxito em viabilizar a equidade na formação de sujeitos sociais (LIBÂNEO; OLIVEIRA; TOSCHI, 2012; SAVIANI, 2011; 2012; ALVES; CANÁRIO, 2004). Essas considerações esbarram na problemática da organização secular do sistema educacional: ao não perceber o estudante como possuidor de curiosidade nata, ocupando-se mais dos métodos e fins do que da aprendizagem e avaliação dos processos, patrocina a apatia do mesmo e recorrentemente, a evasão escolar e/ou a reprodução de analfabetos funcionais. É uma ação educativa asséptica, estéril, reprodutiva de paradigmas e, que acredita que a escola pode permanecer separada e não é (será) influenciada pela realidade sócio-histórica-político-cultural da humanidade (MACEDO, 2017; FERREIRA, 2006; LIBÂNEO, 2002).

Essa discussão já estava sendo gestada na época da implementação dos Parâmetros Curriculares Nacionais (PCN) apresentados como instrumentos de orientação para os professores diante das dificuldades nas tratativas de temas que margeiam os conteúdos programáticos tidos como inter/transdisciplinares (LOPES, 2002; GALLO, 2004; BRASIL, 1999). A elaboração dos PCN, considerados divisores de águas na discussão institucionalizada sobre contextualização e transversalidade, surgiu como uma resposta às pesquisas que apontaram que os estudantes não correlacionavam os conteúdos das aulas com o cotidiano (POZO; CRESPO, 2009; MACEDO, 1999). A organização dos conhecimentos científicos a partir da concepção curricular fechada das disciplinas se apresentara como insuficiente para integrar realidades, contextos, saberes prévios e elaborados no ensino-aprendizagem.

As argumentações acima relatadas foram tomadas, em parte, para impulsionar movimentos que se apresentaram como a salvação da educação básica, com velhos discursos, porém, de caráter de re(estruturação) curricular, como a implementação, controversa, da Base Nacional Comum Curricular (BNCC). Os saberes escolares devem conduzir aos conjuntos de competências e habilidades que serão desenvolvidos nas escolas, sob responsabilidade dos professores. Dessa forma, espera-se a produção de um ensino mais eficaz, que atenda às necessidades atuais (CURY, 2019; MARIUZZO; MORALES, 2018; APPLE, 2011). 
Nesse cenário, algumas conjunturas precisam ser pontuadas: no primeiro plano, o modo como alguns elementos estruturam o ensino formal (organização dos conhecimentos, avaliações e prática docente) se dissemina também para o tratamento dos temas transversais, mesmo que grosso modo se tente imprimir uma apresentação inter/transdisciplinar emergencial que na análise de Minayo (2011) está mais para abordagem multiprofissional.

No segundo plano, a inclusão da análise sociológica nos processos educativos inaugurou a visão sobre como a estrutura social e as políticas públicas não podem ser ignoradas ao se aferir o impacto das propostas educativas na formação de cidadãos (FERREIRA, 2006). Por isso, passou-se a questionar ações centradas na formação intelectual alienada dos problemas concretos e que invariavelmente acondicionavam as mesmas condições sociais dos indivíduos, isto é, a escola como local de reprodução das desigualdades, como inapta de prover respostas para os anseios de um determinado recorte situacional (SAVIANI, 2008; 2011; ALTHUSSER, 1987). A perspectiva instrucionista se ocupa em tornar a aprendizagem um veículo de capacitação para reprodução/treinamento sem que haja uma preocupação em fomentar o pensamento. Já a dialética é o caminho mais adequado para a interpretação da realidade, pois a percebe como objeto concreto formada por múltiplas determinações (DEMO, 2005).

Por exemplo, em tempos de reincidências de algumas doenças tanto pelo aumento da adesão a grupos antivacinas impulsionados por fake news como aquelas ocasionadas por desastres ambientais, emerge a salvaguarda de ações que flertam com as que obtiveram sucesso no passado contra agravos como a peste, febre amarela e dengue dirigidas pela polícia sanitária (PAIM, 2007) sem considerar as mudanças sociais de comportamento que não mais favorecem intervenções que são mais punitivas do que educativas. O tema transversal saúde requer retorno à sua gênese, às reformulações socioculturais e ambientais que submetem a escola e comunidades às novas configurações socioeconômicas e políticas, os chamados determinantes da saúde (CARRAPATO; CORREIA; GARCIA, 2017; FIOCRUZ, 2008; SCLIAR, 2007). Os indivíduos são reticentes a propostas de intervenção verticalizadas, questionam a validade das ciências e, em parte, porque não as compreendem ou não são incluídos em discussões significativas dentro ou fora da escola. Ao se sentirem excluídos, 
marginalizados, tomam decisões que são responsáveis pela perpetuação das situações de risco e perigo para o bem-estar coletivo.

Diante do exposto, o objetivo deste artigo é discutir as práxis da educação em saúde mediante reflexões epistemológicas. Advém do pressuposto que a inclusão dos temas geradores freirianos conduzem a contextualização e aproximação sociocultural entre as subjetividades dos sujeitos e o que preconiza a Educação em Saúde (BRASIL, 2007). Aponta também a necessidade de quebra de paradigmas sobre o modelo atual de educação/ensino, reorientando as práticas docentes para a interdisciplinaridade em uma sociedade pós-moderna (ASSMAN, 1998).

Portanto, trata-se de uma pesquisa qualitativa e de análise teórica, sendo justificada posto que são acanhadas produções acadêmicas que aproximem as Ciências Humanas na discussão do tema saúde, direcionadas para a educação básica. Os sujeitos que se predispõem a falar do tema saúde na escola são em sua maioria da Saúde e Ciências Biológicas e que embasam suas ações em referenciais epistemológicos dessas áreas, com exígua comunicação entre os autores da Educação, Ensino e Educação em Saúde. O método escolhido foi o de revisão narrativa segundo Rother (2007) por atender os objetivos do trabalho e permitir a interlocução entre as percepções das autoras durante a análise e os textos selecionados.

As discussões serão apresentadas em três blocos: no primeiro, defendemos uma educação pautada no diálogo e no reconhecimento da multiculturalidade, ou seja, uma nova Pedagogia que possa ser incorporada na Educação em Saúde; no segundo, uma breve reflexão sobre os temas geradores freirianos e, por último, a proposta de trabalhar tópicos recorrentes do enfrentamento de agravos como temas geradores na Educação em Saúde.

\section{Em defesa de uma Pedagogia Dialógica, contextualizada e multicultural}

Se, no início do século XX o desafio imperativo consistia em prover a inclusão de crianças e jovens na escola formal, atualmente o debate é sobre o que se tem ensinado e como se tem aprendido. Essas discussões esbarram no modelo fordista de educação cujos objetivos e métodos não são congruentes para a inserção de sujeitos em uma sociedade com novas demandas para o mercado de trabalho e formação crítica interdisciplinar (SAVIANI, 2011; 2008; ARANHA, 2006; ALVES; CANARIO, 2004). 
$\mathrm{E}$, dentre esses desafios, duas perguntas dão início às reflexões: i) como as transformações técnico-científicas e socioculturais fomentam uma nova sociedade do conhecimento? ii) e, a partir dessa observação, como intermediar as relações entre vivências/mundo dos discentes e a os saberes científicos discutidos na sala de aula, contribuindo para uma formação autônoma dos sujeitos?

Assim como Kuhn (1970) fala das revoluções científicas como eventos responsáveis por mudanças radicais nas ciências, com quebras de paradigmas e a elaboração de novos padrões de similaridade, Hall (1997) denomina como virada cultural um conjunto expressivo de ações ocorrendo simultaneamente, em um curto espaço temporal, infringindo reestruturações significativas na forma como os indivíduos se organizam. Vide as novas formas de linguagens, impulsionadas pelas redes sociais e o acesso e difusão de conhecimentos, não mais compreendidos como anteriormente. O comportamento das massas, antes ditado pelos programas de televisão, apontam a necessidade para se conhecer como os sujeitos entendem e interferem (e são manipulados) nos aspectos sociais por meio de pequenos textos que se propagam massivamente na Internet. Contraditoriamente, ao mesmo tempo que as novas tecnologias promovem a comunicação rápida, a cura de agravos, a produção de medicamentos e vacinas, e o (in)questionável aumento do agronegócio, vêm produzindo os excludentes do novo milênio que não tem poder monetário, educacional, tecnológico e cultural para acessar e entender essas dinâmicas (CASTELLS, 2017; LARRETA, 2003; CARVALHO; KANISKI, 2000).

$E$, como qualquer outra instituição, a escola contemporânea mesmo que ainda siga alguns signos operacionais do século passado é sensível a essas transformações. Mais do que isso, para alguns autores, está a serviço nas tentativas (frustradas) de condicionar os estudantes a um modelo cultural único porque acredita que ao fazê-lo torna mais factível que os mesmos acessem o mundo globalizado e possam dele usufruí-lo (MOREIRA; CANDAU, 2003). E lança mão do professor cuja ação é uma prática social, carregada de sentidos tanto para quem a realiza como para quem observa ou é alvo dela, portanto, é um modo de cultura. Como cultura, estrutura pensamentos e comportamentos, sendo também objeto de intervenção (ARROYO, 2000; TARDIF, 2000; GIROUX, 1997). 
Assertivamente, Candau (2014) denuncia a preponderância do discurso escolar sobre as demais formas de expressão cultural quando a escola confunde promover a igualdade com homogeneização dos sujeitos e, diz que

Todos e todas são chamados a participar do sistema escolar, mas sem que se coloque em questão o caráter monocultural e homogeneizador presente na sua dinâmica, tanto no que se refere aos conteúdos do currículo quanto às relações entre os diferentes atores, às estratégias utilizadas nas salas de aulas, aos valores privilegiados etc. (CANDAU, 2014, p.26).

Ou seja, as diferenças que conseguem resistir a esse processo homogeneizador são silenciadas. Na educação escolar, os saberes oriundos das camadas populares não encontram, salvo raras exceções, lugar para fomentarem momentos de discussão crítica e formativa (MONTEIRO, 2002). Para Moreira e Candau (2014), a relutância do corpo docente e dos demais setores da escola em reconhecer as diferenças multiculturais que disputam espaço na escola recebe a designação de daltonismo cultural.

Para combater o silenciamento, Candau (2014) percebe as singularidades como indispensáveis ao ambiente escolar, por oportunizarem momentos de riqueza didática e orienta os professores a buscarem a existência das porções de cultura, não melhores ou piores, mas complementares, ou como apontam Lipovetsky e Serroy (2011), partes constituintes da cultura-mundo. Portanto, não cabe fazer uma incursão sobre as diferenças identificando-as como desafios para uma busca frenética de homogeneização, sob a ótica de que a

[...] cultura popular e diferença social podem ser vistas pelos educadores [...] como [...] um terreno em que nos devemos reunir com nossos alunos para uma experiência pedagógica capaz de ativar, e não desativar, a imaginação e as capacidades humanas em benefício da alegria individual, da prosperidade coletiva e da justiça social (GIROUX; SIMON, 2011, p. 128).

Sobre essa capacidade de ativar imaginações é necessário, segundo Monteiro (2002), perceber as peculiaridades do trabalho docente divergente do trabalho científico. Esse trabalho ocorre em um espaço multicultural, que deve abarcar as diferenças e que não deve objetivar uma cristalização de pensamentos, mas estimular as inquietações dos indivíduos. Sem inquietações não ocorre aprendizagem, fenômeno esse que deve ser permanente, dentro e fora do ambiente formal de ensino. $E$, 
portanto, exercer a docência destoa da prática descuida, fechada em si, desconectada do mundo real, alicerçada em teorias retalhadas (PAVIANI, 2009).

Assim, sabendo que a atividade educacional é práxis intencional, compreender as finalidades desse processo é de suma importância. Se tanto a intencionalidade quanto a finalidade perpassam pelo campo político alguns pontos devem ser colocados: a partir, então da compreensão sobre os elementos formadores da educação não circundarem o sujeito, mas fazerem parte e/ou emergirem dele, Saviani (2011) problematiza quais seriam os caminhos mais indicados para se conhecer o outro, as culturas circundantes e, deste modo, levar ao construto histórico da humanidade. Ou seja, intencionar ações educativas inclusivas e dialógicas que se lancem a questionar por que os fenômenos ocorrem, relacionando-os com os temas/objetos em discussão. A sala de aula não pode configurar-se como campo distal da realidade dos estudantes, nem inferior/superior, mas como uma ponte entre as diversas perspectivas e pensamentos.

Se para atender a demandas de uma sociedade técnico-científica globalizada os novos discursos apostam mais na competividade do que na colaboração a pedagogia dialógica e multicultural pautadas na interlocução permanente busca caminhos conciliadores entre a formação científica e técnica com preceitos de igualdade, democratização dos saberes, trabalho em rede e compartilhamento de responsabilidades (GIROUX; SIMON, 2011). Percebe que em um trabalho educativo cada indivíduo é mais do que um participante ou emissor/receptor de mensagens; são sujeitos sociais, com lugar de fala e de escuta e, por isso, partem de suas percepções de mundo para (re)interpretarem a realidade.

E estas percepções de mundo podem ser os temas geradores em uma educação em saúde que prima pela formação autônoma e não reprodutiva dos saberes institucionalizados.

\section{Os temas geradores de Paulo Freire e a oportunização da fala}

A propósito do discutido anteriormente, em defesa de uma educação contextualizada, multicultural e politizada, no sentido de reconhecê-la como instituição e sociedade, temos que questionar "[...] sobre o que vem sendo o papel da 
escola e dos professores na produção de saberes, na sua relação com o conhecimento" (LIBÂNEO, 2002, p.11).

Paulo Freire (1979; 1996; 2009), ciente da atribuição política da educação, e que essa, por meio da escola, não se ocupa apenas da formação acadêmica do indivíduo, promoveu métodos contra hegemônicos aos modelos tradicionais de ensino. Apontou que está no sujeito social e não em documentos instrucionais a resposta para promover a formação cidadã.

Na opinião de Lorenzon, Barcellos e Silva (2015) a perspectiva freiriana veio para viabilizar um debate sobre o modelo de ciência dogmática que implica em desacreditar o entendimento dos sujeitos, tentando impor-Ihes um conjunto de saberes como uma única verdade, produzindo, sujeito opressor e sujeitos oprimidos. Do ponto de vista de Auler (2007), essa ciência dogmática sustenta um ensino propedêutico que apesar de acúmulos sucessivos de anomalias insiste em ser o modelo atual para as práticas no ensino e, mesmo sendo constatado, que promove insubmissão já que sujeito e objetos são refratários (SACRISTÁN, 2000).

Ou seja, a discussão/diálogo em sala de aula deve ser uma constante em paralelo ao fomento da curiosidade e questionamentos, sendo, portanto, desestimulada a busca pela lógica porque, ela, segundo Shio (2009) é construída a partir de métodos que a tornam inquestionável. Ao se retirar a possibilidade de questionamentos nas aulas o professor perde a adesão e curiosidade dos estudantes, elementos essenciais para a interação educativa.

Dessa forma, para promover interesse sobre o tema/objeto, professor e estudantes devem, em primeiro lugar, instaurarem um consenso sobre os objetivos de aprendizagem e, segundo, suscitarem a problematização e a contextualização (SHIO, 2009). E se o tema a ser discutido emergisse do estudante, ao sentir suficientemente acolhido a ponto de compartilhar seus pontos de vista e, a partir do diálogo, a problematização emergisse? Esse é o pilar fundador dos temas geradores de Freire (2009).

A partir dos temas geradores extingue-se a marginalização dos saberes dos sujeitos e de sentimentos de inferioridade quando os saberes ditos científicos e comuns são planificados. Os saberes comuns são representações concretas dos anseios e percepções de indivíduos e/ou grupos sobre um determinado recorte da 
realidade (Figura 1), onde os participantes obtêm a oportunidade para questionar as atitudes individuais e coletivas pensando em como transpor a teoria para a prática e vice-versa (LORENZON; BARCELLOS; SILVA, 2015; TOZONI-REIS, 2006).

Figura 1 - Concepção dos temas geradores e a produção de sentidos.

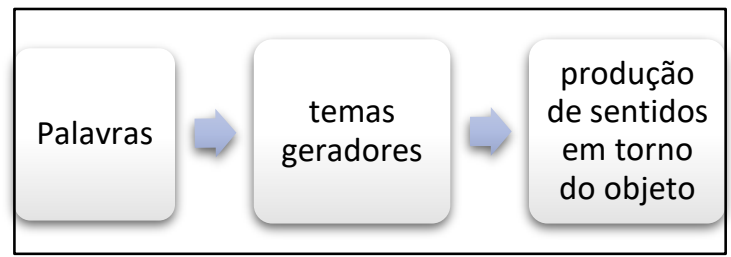

Fonte: Elaborado pelas autoras.

Indubitavelmente, a introdução dos temas geradores deve derrubar paradigmas: 1 ) os estudantes encontram-se em um vazio de conhecimentos; 2) os estudantes são aculturados e, 3) um ensino pasteurizado, homogêneo, tecnicista é o mais adequado para o mundo conectado, informatizado e tecnológico (CANDAU, 2014; STRECK, 2012; GIROUX; SIMON, 2011; MONTEIRO, 2002).

Os estudantes não estão em um vazio de conhecimentos e/ou aculturados pois são, sujeitos históricos e, portanto, produzem cultura. Falar dos temas geradores é estar preparado para realizar uma imersão nas representações sociais que os estudantes apresentam por meio da fala, do comportamento, no silêncio e nos gestos. Não é uma escuta vazia, tampouco uma superficial autorização para emissão de opiniões, mas a busca por temas que possam problematizar os objetos.

O conceito de inacabado não deve promover o pensamento sobre um sujeito a ser terminado ou preenchido, mas como uma pré-condição para mediação possibilitando que "[...] alunos e alunas se transformem, com o ensino que fazemos em homens e mulheres mais críticos" (CHASSOT, 2003, p. 63). Acima de tudo sinaliza que o homem só se torna completo por meio dos movimentos históricos e sociais que ele mesmo produz, sendo a educação um dos processos indissociáveis para a sua formação, pois "ou nos educamos e alcançamos a constituição humana ou deixamos de educar-nos permanecendo num estágio de animalidade elementar" (FULLAT, 1994, p.85). Mas, por outro lado, se vejo o outro e a mim como seres inacabados percebo que a ética, o cuidado, o respeito e a preparação para autonomia são indissociáveis da prática pedagógica. 
Assim, a investigação dos temas geradores não parte de uma incursão solitária do educador, mas de sujeitos socioculturais, das múltiplas interpretações, da ação educativa dialógica, o que na argumentação freiriana seria como

[...] o pensamento do homem sobre a realidade e a sua ação sobre esta realidade que está em sua práxis. Na medida em que os homens tornam uma atitude ativa na exploração de suas temáticas, nessa medida sua_consciência crítica da realidade se aprofunda e anuncia estas temáticas da realidade (destaques nossos) (FREIRE, 1979, p.18).

De fato, os temas geradores só podem ser identificados por meio de interações entre os envolvidos e o objeto e, portanto, a perspectiva sobre as ciências que os docentes têm facilitam ou não essa mediação. Se os docentes, no papel de mediadores, partem de uma perspectiva de ciência como fato posto, verdade inabalável e construto a-histórico, a educação não será emancipadora como orienta Freire (MIRANDA; PAZZINATO; BRAIBANTE, 2017).

A oportunização da fala, defendida por Freire (2009), pode ser prevista e implementada sendo exíguo pensar a partir dos homens e mais: uma cinesia em torno de uma compreensão da realidade complexa. Não se pode buscar pelos homens, pelo outro, falar pelo outro, mas empreender um resgate de temas dessa realidade complexa, movimento que só será completado quando houver de fato compreensão (TOZONI-REIS, 2010; MOREIRA, 2004; FREIRE, 1996; SANTOS; EL-HANI, 2017).

Todavia, quando professores assumem uma postura crítico-transformadora da sua prática buscando mais do que colaborações, mas a inserção do outro com os mesmos direitos de fala, então se torna factível alavancar soluções integradas para um determinado campo do conhecimento (CONRADO; QUADRO, 2014). Essa integração do homem/contexto conduz a uma reflexão entre os sujeitos envolvidos e "leva respostas aos desafios que se lhe apresentam, cria cultura" (FREIRE, 1979, p. 20).

Dessa prática educativa emerge o professor revolucionário e político percebendo que a forma como se apresenta a dinâmica do ensino é fundamentada na liberdade em ver a escola como meio para impor-se contra uma ideologia dominante que perpetua diferenças de classes e a manutenção de condições de vida pautada pelas desigualdades (BERNARDINO, 2010; ALTHUSSER, 1999).

Além disso, Cescon (2009, p. 15) caracteriza a função docente como aquela que não limita-se a transferir conhecimentos mas que em seu cotidiano promove o que ele 
chama de interações educativas nas quais percebe-se a necessidade de aproximar o aluno da escola e não torná-lo submisso aos processos educativos, retirando a sua individualidade, o que para Saviani $(2011$, p.6) contradita-se pois "o trabalho educativo é o ato de produzir, direta e intencionalmente, em cada indivíduo singular, a humanidade que é produzida histórica e coletivamente pelo conjunto dos homens".

Da mesma forma, Lagarón (2014, p. 2) insiste que o aprender (no âmbito da investigação científica) é exitoso se o professor promover estratégias para manter o aprendiz ativo e curioso. Defende que não se pode confundir o desenvolvimento de habilidades interpretativas e de investigação com "habilidades procedimentales de tipo técnico-manipulativo, tales como medir, observar, hacer una gráfica".

A propósito, verificar com os alunos a realidade concreta vai ao encontro da inclusão do respeito e reconhecimento que os indivíduos têm lugar de fala sobre os temas que emergem das suas experiências e problemáticas cotidianas. $E$, é por meio dos temas geradores e de uma prática emancipadora que se pode prover a transformação do homem para sujeito que é histórico, político, protagonista e tem voz (FREIRE, 1996).

Em síntese, pensar nos temas geradores é estar pronto para os desafios da diversidade cultural que é um movimento para além da mera inclusão do ponto de vista hierárquico da voz do estudante; é trabalhar com as multidimensões dos saberes (MOREIRA; CANDAU, 2014), uma tentativa contínua de resgatar a diversidade cultural, o que para Giroux e Simon (2011, p.134), "significa trabalhar com o conhecimento embutido nas formas de sociabilidade, nas comunidades de discurso e nas formas de expressão popular a que os alunos atribuem significados [...]". Cabe, portanto, que a escola e seus atores sociais reconhecerem os significados como produções legitimas e com igual valor, não maiores ou menores, para serem incluídos nas práticas de aprendizagem, ora como instrumentos de mediação pedagógica ou como oportunidade de se ingressar nas realidades distais da escola.

\section{Os tópicos de saúde como temas geradores na educação em saúde}

Os significados, sobre os objetos saúde e doenças, elaborados pelos indivíduos estão imersos em uma rede complexa de subjetividades não compartilhadas ou percebidas em uma educação silenciadora, como já discutido. A partir da análise 
socioantropológica da saúde é possível distinguir as singulares expressões culturais sobre o corpo, a morte, o ambiente, os ritos, os hábitos alimentares e de higiene que se proliferam no mesmo bairro, cidade e nos grupos familiares (MINAYO, 2012; RODRIGUES, 2005; MAUSS, 2003; MARTINS, 2003). Por sua vez, falar de saúde no, e para além do, currículo e disciplinas, requer além da existência de uma base comum de conteúdos, distribuição de medicamentos, panfletos, jogos e recursos multimídias ou verificação da caderneta de vacinas. Demanda oportunizar o reconhecimento do outro e a visualização do território como fatores em constante mutação e, assim como os condicionantes/determinantes da saúde, todos que dividem ou não um espaço, também são influenciados por sua dinâmica e re(construção) (CARVALHO, 2015; FALKENBERG et al., 2014).

Não se deve cair no reducionismo e negar a importância das ações de prevenção de doenças mencionadas, principalmente para as cidades mais desfavorecidas e afastadas dos grandes centros ou ainda aquelas assoladas por doenças reincidentes do século retrasado. Porém, são atendimentos pontuais frente a epidemias ou surtos no lugar do planejamento e discussão da saúde como orientados pelos documentos da Promoção da Saúde (RIBEIRO et al., 2018; JARDIM; SHALL, 2009; CLARO; TOMASSINI; ROSA, 2004). Alguns autores têm descrito o insucesso no enfrentamento de doenças como tuberculose, para a qual é recorrente o abandono do tratamento antes do prazo estabelecido, mesmo em locais onde há medicamentos disponíveis e acompanhamento dos agentes comunitários de saúde (MENDES; FENSTERSEIFER 2004; ROCHA; ADORNO, 2012).

A dengue e o seu vetor Aedes aegypti que já foram erradicados do Brasil em meados de 1950, não só foram reintroduzidos no território, como o vetor tem disseminado os vírus para a febre amarela urbana, a Zika e a Chikungunya (VALLE; PIMENTA; AGUIAR, 2016; CHIEFFI, 1985). No caso da febre amarela, a única das arboviroses associadas ao Aedes que tem vacina disponível, o baixo índice de adesão as campanhas de vacinação alertaram as autoridades governamentais sobre a necessidade de convocar a população, ampliar a divulgação de como as vacinas são seguras e importantes para o bem coletivo e o entendimento sobre os animais sentinelas (como os macacos) que devem ser vistos como aliados e não perseguidos pela população (VALE; JUNIOR; PREZOTO, 2018; FIOCRUZ, 2018; BARBIERI; COUTO; 
AITH, 2017). Mas, porque essas problemáticas ocorrem apesar dos avanços da medicina, dos meios de produção e divulgação de pesquisas sobre os temas de saúde em vários tipos de mídias?

Fazendo uma retrospectiva histórica é possível constatar a introdução do tema saúde nas escolas brasileiras com modus operante similar ao da Alemanha, que adotou o projeto Saúde Escolar cujos objetivos consistiam na mudança de comportamentos dos escolares, por meio da imposição de orientações e prescrições de atitudes para alcançar níveis de saúde estabelecidos pelo Governo (FIGUEREDO; MACHADO; ABREU, 2010). As ações docentes e das equipes de saúde ocorriam dentro da perspectiva biomédica, inspeção sanitária e verificação das condições clínicas (pesagem e medição, produção de diagnóstico e encaminhamento dos escolares para os serviços de saúde). Gradativamente, o tema saúde, deixou as cartilhas de saúde e foi inserido nos documentos normativos e livros didáticos. Apesar das tentativas de conciliar as ciências biomédicas e ciências sociais e humanas para falar sobre saúde e doenças, na prática, ocorriam discursos verticalizados, mecanizados, voltados exclusivamente para a decoreba de ciclos das doenças, como reconhecê-las, como evitá-las, periodicamente acompanhados de inspeção sanitária nos lares e escolas e, distribuição de materiais de higiene pessoal (MONTEIRO, 2012; SILVA, 2010; REIS, 2006; ROCHA, 2003).

Os insucessos que as ações em saúde têm acumulado podem ser entendidos pois os discursos são desconexos dos locais para onde são emitidos; a proposição verticalizada de informações; ações descontínuas para atender ora a períodos epidêmicos ou os agravos pontuados pela mídia e a criminalização dos acometidos como os únicos responsáveis pelos seus estados de saúde/doença (CZERESNIA; FREITAS, 2009; NUNES; PIMENTA, 2010).

Em razão do exposto, por que é plausível falar dos temas geradores na Educação em Saúde? No enfrentamento de agravos há dois tipos de condicionantes para os estados de saúde: os externos a realidade do homem e aqueles internos, próprios da dinâmica local. Em geral, os temas da saúde que balizam uma determinada intervenção são oriundos apenas dos condicionantes externos embasados por dados epidemiológicos. Os fatores próprios da realidade e história contextualizada que poderiam dar origem aos temas geradores nem são dialogizados. Consequentemente, temas como agentes causadores/ transmissores, ciclo, hospedeiros intermediários/ 
definitivos, epidemias, surtos e endemias, dentre outros, são tratados como objetos fechados em si, provocando: i) a não inclusão de outros setores da sociedade na discussão sobre saúde em razão do enfoque biomédico; ii) distanciamento dos estudantes de uma formação autônoma já que estes apenas recebem as informações, sendo considerados ineficientes de participarem dos processos decisórios.

Esses temas supracitados são construções históricas, interdependentes e que variam em sentidos no tempo, espaço e nos mais diferentes grupos que estão inseridos. O que se defende, é a gêneses, identificação e desenvolvimento de temas geradores a partir dessas temáticas primárias para então emergirem os contornos reais (questões não claras de um objeto e que fogem do escopo técnico de um campo teórico) e que são essenciais na compreensão das subjetividades da saúde (MINAYO, 2013). É a busca por esses contornos que irá conduzir aos temas geradores em saúde como por exemplo, a formação do território e saúde, o ambiente e os aspectos socioculturais, as percepções populares sobre cuidados individuais, vida social e espaços públicos, a reivindicação de formulação de políticas públicas, dentre outros.

Todavia, os temas geradores como ação política social da educação em saúde podem conduzir ponderações sobre as possibilidades e novos desafios na formulação de ações que promovam a intercessão escola-saúde-indivíduos-ambiente. Constituem uma forma metodológica de ação em que a imersão em busca da compreensão dos processos que regem os agravos perpassa para além do trinômio causa-doença-cura (FREIRE, 1979). Ademais, levantam uma pergunta tão perturbadora tal qual a questão encontrada no trabalho de Streck (2012): como intercambiar as experiências dos estudantes com o preconizado no currículo/plano de trabalho?

As experiências estudantis deparam-se com as relações de dominância que determinam a legitimidade dos discursos aceitos no espaço escolar, encontrando pouco ou nenhum espaço para interagirem (GIROUX; SIMON, 2011). A propósito, para muitos "tratar de temas do senso comum, [...] seria sucumbir à lógica do sistema, como se problemas da vida interna da escola e da sala de aula fossem questões menores" (LIBÂNEO, 2002, p.16). A forma como os estudantes recebem os conteúdos e interagem com eles, se não estiver adequada ao almejado pela cultura escolar, recebe a denominação de ilegítima porque advém da cultura popular (GIROUX; SIMON, 2011). 
Decerto, abraçar realidades contrastantes é inerente a quem predispõe-se a fazer uma incursão por meio da educação em um recorte contextual, histórico e temporal. Mais do que aproximação pontual no novo, cabe ainda ser capacitado para a interpretação das subjetividades e prover condições para que todos os sujeitos participantes estejam conscientes de seus papéis. A interpretação é indissociável ao estudo, tendo em vista que

não se pode estudar qualquer realidade sem interpretá-la. Observar mais que formal que possa querer ser, também é interpretar. A razão pode ser mais simples: somos sujeitos, não objetos; entidades subjetivas hermenêuticas (DEMO, 2005, p. 37).

É sobre esse reconhecimento dos homens como sujeitos de qualquer ação proposta e na contramão do modelo de educação que fala de saúde sustentada apenas no tripé vetor - patógeno - doença, que Briceño-Leon (1996), defende na ação educativa conhecer e contar com o ser humano e, no texto Siete tesis sobre la educación sanitaria para la participación comunitária, enumera os postulados a seguir como centrais para a educação em saúde: i) a educação também é importante na ação sanitária (a educação mencionado por Briceño-Leon (1996) é o campo, com suas teorias e práticas); ii) a falta de conhecimento (ignorância) dos sujeitos é algo a ser transformado; iii) todos os sujeitos sabem alguma coisa; iv) a educação deve ser dialógica e participativa; v) a educação deve reforçar a confiança dos sujeitos em si mesmos; vi) A educação deve procurar fortalecer o modelo de conhecimento: esforçorealização; vii) A educação deve fomentar a responsabilidade individual e a cooperação coletiva. Essas setes teses convergem com a Educação em Saúde (que atende a formação individual do sujeito) e a Promoção da Saúde (ocupada em promover o bemestar coletivo), campos construídos a partir dos ideais que geraram as Conferências Nacionais e Internacionais em Saúde e com os preceitos freirianos para uma educação emancipatória. Apontam para novas perspectivas nos discursos sobre saúde para a qual a interação e o entendimento com/sobre o ambiente são ações essenciais. É um exercício frequente de voltar para si, para os outros e para o meio onde está inserido (CANDEIAS, 1997).

O indivíduo é peça central e fundamental de qualquer processo assim como o pensamento, forma de ver a vida, suas relações com o meio ambiente, família e comunidade, constituindo fatores moduladores da saúde. Conhecê-lo é o ponto de 
partida para qualquer ação da educação em saúde. Os temas da saúde só podem ser entendidos quando resgatados da realidade onde são produzidos por meio da sequência pautada na decisão coletiva, cooperativa e dialógica.

\section{Considerações finais}

O enfrentamento de agravos a saúde tem requisitado a convocação de setores diversos e a escola encontra-se no centro dadas as suas características de produção e divulgação de conhecimentos, bem como moduladora de cultura. É espaço permanente de formação e, apesar dos problemas contemporâneos enfrentados, ainda se apresenta como ponto de referência para a sociedade. Porém, as dificuldades de estabelecer diálogo pautado no respeito mútuo na presença de diferenças têm silenciado a voz dos estudantes. Por isso, práticas verticalizadas pautadas na obediência sem entendimento crítico estão cada vez mais direcionadas para o fracasso. Toma-se nota que as questões em saúde exigem mais do que disponibilizar informações e procedimentos para um determinado grupo. Desloca-se do campo das competências técnicas que se ocupam em transmitir saberes sobre as infecções e como evitá-las para o questionamento sobre os fatores que modulam os condicionantes da saúde tão instáveis e complexos.

Os sujeitos, ao vivenciarem as mazelas das doenças, direta ou indiretamente, carregam uma bagagem cultural que por muito tempo não foi considerada como possível de conectar com o que é discutido na escola. As percepções e as experiências, os sucessos e os insucessos, são descartados porque já estão estigmatizados como de pouco valor pelos que se predispõem ou são requisitados a falar sobre saúde na escola e comunidades.

Dessa forma esse trabalho ocupou-se em abordar dois desafios: estimular a introdução dos temas geradores na prática educativa e transpor essa ideia para a educação em saúde, um campo de silêncios e de repasse de informações. Se o docente ou qualquer outro sujeito social se prontificar a fazer uma incursão na identificação dos temas geradores na educação em saúde, sua ação será cultural e histórica porque só assim será possível fazer os desdobramentos necessários para fomentar discussões entre os sujeitos envolvidos. Entretanto, para a inserção de práticas que sejam dialógicas por meio dos temas geradores é vital problematizar o tipo de educação que 
está posta e disponível, desde a formação dos professores, suas condições de trabalho, os materiais e recursos e a cultura sociopolítica que guia os rumos do ensino, para os quais a escola mesmo que tente se esquivar, é ambiente submisso, modulável e influenciado. Cabe um olhar mais próximo do contexto, do indivíduo, para além das respostas prontas emitidas para avaliações, questionários de pesquisa ou de levantamento de dados pontuais.

Em síntese, considera-se pertinente finalizar esse trabalho com Lipovetsky e Serroy (2011), ao considerarem a importância da prática docente que se preocupa em oferecer "uma multiplicidade de projetos, de experiências e de horizontes de sentido, dar-lhes a possibilidade de 'mudar a vida'".

\section{Referências}

ALTHUSSER, L. Aparelhos ideológicos de Estado. Rio de Janeiro: Edições Graal, 1987.

ALTHUSSER, L. Sobre a reprodução. Petrópolis: Vozes, 1999.

ALVES, N.; CANÁRIO, R. Escola e exclusão social: às incertezas. Análise Social, Lisboa, v. 28, n. 169, p. 981-1010, 2004.

APPLE, M. W. A política do conhecimento oficial: faz sentido a ideia de um currículo nacional? In: MOREIRA, F. A.; TADEU, T. (org.). Currículo, cultura e sociedade. São Paulo: Cortez, 2011.

ARANHA, M. L. A. História da educação e da pedagogia: Geral e Brasil. São Paulo: Moderna, 2006.

ARROYO, M. Ofício de mestre: imagens e auto-imagens. Petrópolis: Vozes, 2000.

ASSMAN, H. Reencantar a educação: rumo à sociedade aprendente. Petrópolis: Vozes, 1998.

AULER, D. Articulação entre pressupostos do educador Paulo Freire e do Movimento CTS: novos caminhos para a educação em Ciências. Revista Contexto e Educação, Unijuí, v. 22, n. 77, p. 167-188, jan./jun. 2007.

BARBIERI, C. L. A.; COUTO, M. T.; AITH, F. M. A. A (não) vacinação infantil entre a cultura e a lei: os significados atribuídos por casais de camadas médias de São Paulo, Brasil. Cadernos de Saúde Pública, Rio de Janeiro, v. 33, n. 2, mar. 2017. 
BERNARDINO, P. A. B. Estado e educação em Louis Althusser: implicações nos processos de produção e reprodução social do conhecimento. 2010. 190 p. Dissertação (Mestrado em Educação) - Universidade Federal de Minas Gerais, Belo Horizonte, 2010.

BRANDÃO, C. R. O que é educação. São Paulo: Brasiliense, 2012.

BRASIL. [Constituição (1988)]. Constituição da República Federativa do Brasil de 1988. Brasília, DF: Presidência da República, 1988. Disponível em: http://www.planalto.gov.br/ccivil_03/Constituicao/Constituiçao.htm. Acesso em: 1 jan. 2020.

BRASIL. Fundação Nacional de Saúde. Diretrizes de educação em saúde visando à promoção da saúde: documento base. Brasília: Funasa, 2007. Disponível em: http://www.funasa.gov.br/documents/20182/38937/Educa\%C3\%A7ao++em+Saude+ -+Diretrizes.pdf. Acesso em: 1 jan. 2020

BRASIL. Ministério da Educação. Secretaria de Educação Média e Tecnológica. Parâmetros curriculares nacionais: ensino médio. Brasília: MEC/SEMTEC, 1999.

BRICEÑO-LEON, R. Siete tesis sobre la educación sanitaria para la participación comunitária. Cadernos de Saúde Pública, Rio de Janeiro, v. 12, n. 1, p. 7-30, jan./mar. 1996.

CANDAU, V. M. Educação intercultural: entre afirmações e desafios. In: MOREIRA, A. F.; CANDAU, V. M. (org.). Currículos, disciplinas escolares e culturas. Petrópolis: Vozes, 2014.

CANDEIAS, N. M. F. Conceitos de educação e promoção em saúde. Revista de Saúde Pública, São Paulo, v. 31, n. 2, p. 209-213, 1997.

CARRAPATO, P.; CORREIA, P.; GARCIA, B. Determinante da saúde no Brasil: a procura da equidade na saúde. Saúde e Sociedade. v. 26, n. 3, p. 676-689, 2017.

CARVALHO, F. F. B. A saúde vai à escola: a promoção da saúde em práticas pedagógicas. Physis, Rio de Janeiro, v. 25, n. 4, p. 1207-1227, 2015.

CARVALHO, I. C. L.; KANISK, A. L. A sociedade do conhecimento e o acesso à informação: para que e para quem?. Revista Ciência da Informação, Brasília, v. 29, n. 3, p. 33-39, set./dez. 2000. 
CASTELLS, M. A sociedade em Rede. São Paulo: Paz e Terra, 2017.

CESCON, E. Professor e escola em risco de extinção. In: RAMOS, F. B.; PAVIANI, J. (Org.). O professor, a escola e a educação. Caxias do Sul: Educs, 2009.

CHARLOT, B. A mistificação pedagógica: realidades sociais e processos ideológicos na teoria da educação. São Paulo: Cortez, 2013.

CHASSOT, A. Alfabetização científica: questões e desafios para a educação. ljuí: Unijuí, 2003.

CHAUÍ, M. A universidade pública sob nova perspectiva. Revista Brasileira de Educação, Rio de Janeiro, n. 24 set/dez. 2003.

CHIEFFI, P. P. Algumas questões decorrentes da reintrodução do Aedes aegypti no Brasil. Cadernos de Saúde Pública, Rio de Janeiro, v. 1, n. 3, jul./set. 1985.

CLARO, L. B. L.; TOMASSINI, H. C. B.; ROSA, M. L. G. Dengue prevention and control: a review of studies on knowledge, beliefs, and practices. Cadernos de Saúde Pública, Rio de Janeiro, v. 20, n. 6, p. 1447-1457, 2004.

CONRADO, B.; QUADROS, S. C. O tema gerador freireano e a construção do conhecimento pelos professores da EJA em Caxias do Sul. In: ANPED SUL: ASSOCIAÇÃO DE PÓS-GRADUAÇÃO E PESQUISA EM EDUCAÇÃO, 5., 2014, Florianópolis. Anais [...]. Florianópolis: ANPED, 2014.

CURY, C. R. J. O Ensino Médio sempre foi a pedra de toque da desigualdade social expressa na desigualdade educacional. FIOCRUZ, 2019. Disponível em: http://www.epsjv.fiocruz.br/noticias/entrevista/o-ensino-medio-sempre-foi-a-pedrade-toque-da-desigualdade-social-expressa-na. Acesso em: 12 ago. 2018.

CZERESNIA, D.; FREITAS, C. M. (org.). Promoção da saúde: conceitos, reflexões e tendências. Rio de Janeiro: Fiocruz, 2009.

DEMO, P. Saber conhecer. São Paulo: Cortez, 2005.

FALKENBERG, M. B. et al. Educação em Saúde e educação na saúde: conceitos e implicações para a saúde coletiva. Ciências e Saúde Coletiva, Rio de Janeiro, v. 19, n. 3, p. 847-852, 2014. 
FERREIRA, R. A. Sociologia da educação: uma análise de suas origens e desenvolvimento a partir de um enfoque da sociologia do conhecimento. Revista Lusofona de Educação, Lisboa, v. 7, n. 7 p. 105-120, 2006.

FIGUEREDO, T. A. M.; MACHADO, V. L. T.; ABREU, M. M. S. A saúde na escola: um breve resgate histórico. Ciência e Saúde Coletiva, Rio de Janeiro, v. 15, n. 2, p. 397402, nov. 2010.

FIOCRUZ. Comissão Nacional sobre Determinantes Sociais da Saúde (CNDSS). As causas sociais das iniquidades em saúde no Brasil. Rio de Janeiro: Fiocruz, 2008. FIOCRUZ. Macacos são sentinelas no enfrentamento da febre amarela. 2018. Disponível em: https://portal.fiocruz.br/noticia/macacos-sao-sentinelas-noenfrentamento-da-febre-amarela. Acesso em: 12 ago. 2018.

FONSECA, M. O Banco Mundial como referência para a justiça social no terceiro mundo: evidências do caso brasileiro. Revista Faculdade de Educação, São Paulo. v. 24, n. 1, jan./jun. 1998.

FRANCO, M. A. R. S. Pedagogia e prática docente. São Paulo: Cortez, 2012.

FREIRE, P. Conscientização: teoria e prática da libertação. São Paulo: Cortez \& Moraez, 1979.

FREIRE, P. Pedagogia da autonomia. São Paulo: Paz e Terra, 1996.

FREIRE, P. Pedagogia do oprimido. São Paulo: Paz e Terra, 2009.

FULLAT, O. Filosofias da educação. Petrópolis, RJ: Vozes, 1994.

GALLO, S. Transversalidade e formação de professores. In: RIVERO, C. M. L.; GALLO, S. (org.). A formação de professores na sociedade do conhecimento. Bauru: Edusc, 2004.

GIROUX, H. A. Professores como intelectuais transformadores. In: GIROUX, H. A. Os professores como intelectuais: rumo a uma pedagogia crítica da aprendizagem. Porto Alegre: Artes Médicas, 1997.

GIROUX, H. A.; SIMON, R. Cultura popular e pedagogia crítica: a vida cotidiana com base para conhecimento curricular. In: MOREIRA, A. F.; TADEU, T. (org.). Currículo, cultura e sociedade. São Paulo: Cortez, 2011. 
HALL, S. A centralidade da cultura: notas sobre as revoluções culturais do nosso tempo. Educação e Realidade, v. 22, n. 22, p. 15-46, jul./dez. 1997.

JARDIM, J. B.; SHALL, V. T. Prevenção da dengue: a proficiência em foco. Cadernos de Saúde Pública, Rio de Janeiro, v. 25, n. 11, nov. 2009.

KUHN, T. S. A estrutura das revoluções científicas. São Paulo: Perspectiva, 1970.

LAGARÓN, D. C. De la moda de aprender indagando a la indagación para modelizar: una reflexión crítica. In: ENCUENTROS DE DIDÁCTICA DE LAS CIENCIAS EXPERIMENTALES, 26., 2014, Huelva. Anais [...]. Huelva: Universidad de Huelva, 2014.

LARRETA, E. R. Transparências obscuras: pensar a complexidade. In: MENDES, C.; LARRETA, E. (org.). Representação e complexidade. Rio de Janeiro: Editora Garamond, 2003.

LIBÂNEO, J. C. Produção de saberes na escola: suspeitas e apostas. In: CANDAU, V. M. (org.). Didática, currículo e saberes escolares. Rio de Janeiro: DP\&A, 2002.

LIBÂNEO, J. C.; OLIVEIRA, J. F.; TOSHI, M. S. Educação escolar: políticas, estrutura e organização. São Paulo: Cortez, 2012.

LIPOVETSKY, G.; SERROY, J. A cultura-mundo: resposta a uma sociedade desorientada. São Paulo: Companhia das Letras, 2011.

LOPES, A. C. Os parâmetros curriculares nacionais para o ensino médio a submissão ao mundo produtivo: o caso do conceito de contextualização. Educação e Sociedade, Campinas, v. 23, n. 80, p. 386-400, set. 2002.

LORENZON, M.; BARCELLOS, G. B.; SILVA, J. S. Alfabetização científica e pedagogia libertadora de Paulo Freire: articulações possíveis. Signos, Lajeado, v. 36, n. 1, p. 71 85, 2015.

MACEDO, E. F. As demandas conservadoras dos movimentos escola sem partido e a Base Nacional Curricular Comum. Educação e Sociedade, Campinas, v. 38, n. 139, p. 507-524, abr./jun. 2017.

MACEDO, E. F. Parâmetros curriculares nacionais: a falácia de seus temas transversais. In: MOREIRA, A. F. B. (org.). Currículo: políticas e práticas. Campinas: Papirus, 1999. 
MARIUZZO, P.; MORALES, A. P. Base nacional comum curricular do ensino médio carece de diálogo com a sociedade. Ciência e Cultura, São Paulo, v. 70, n. 2, abr./jun. 2018.

MARTINS, P. H. Contra a desumanização da medicina: crítica sociológica das práticas médicas modernas. Petrópolis: Vozes, 2003.

MAUSS, M. Sociologia e antropologia. São Paulo: Cosac Naify, 2003.

MENDES, A. de M.; FENSTERSEIFER, L. M. Tuberculose: porque os pacientes abandonam o tratamento?. Boletim de Pneumologia Sanitária, v. 12, n. 1, p. 27-38, 2004.

MINAYO, M. C. S. Contribuições da antropologia para pensar e fazer saúde. In: CAMPOS, G. W. S. (org.). Tratado de saúde coletiva. São Paulo: Hucitec, 2012.

MINAYO, M. C. S. Da inteligência parcial ao pensamento complexo: desafios da ciência e da sociedade contemporânea. Revista Política \& Sociedade, Florianópolis, v. 10, n. 10, out. 2011.

MINAYO, M. C. S. O desafio do conhecimento: pesquisa qualitativa em saúde. São Paulo: Hucitec, 2013.

MIRANDA, A. C. G.; PAZINATO, M. S.; BRAIBANTE, M. E. F. Temas geradores através de uma abordagem temática freiriana: contribuições para o ensino de ciências. Revista de Educação, Ciências e Matemática, Rio de Janeiro, v. 7, n. 3, p. 73-93, set./dez. 2017.

MONTEIRO, A. M. A prática de ensino e a produção de saberes na escola. In: CANDAU, V. M. (org.). Didática, currículo e saberes. Rio de Janeiro: DP\&A, 2002.

MONTEIRO, P. H. N. A saúde nos livros didáticos no Brasil: concepções e tendências nos anos iniciais do Ensino Fundamental. 2012. 210 p. Tese (Doutorado em educação) - Universidade de São Paulo, São Paulo, 2012.

MOREIRA, A. F. B.; CANDAU, V. M. Apresentação. In: MOREIRA, A. F.; CANDAU, V. M. (org.). Currículos, disciplinas escolares e culturas. Petrópolis, RJ: Vozes, 2014. 
MOREIRA, A. F. B.; CANDAU, V. M. Educação escolar e cultura(s): construindo caminhos. Revista Brasileira de Educação, Rio de Janeiro, n. 23, p. 156-168, maio/ago. 2003.

MOREIRA, M. A. A epistemologia de Maturana. Ciência \& Educação, Bauru, v. 10, n. 3, p. 597-606, 2004.

NUNES, J.; PIMENTA, D. N. A epidemia de Zika e os limites da saúde global. Lua Nova, São Paulo, v. 98, p. 21-46, 2010.

OLIVEIRA, R. P. A transformação da Educação como mercadoria no Brasil. Educação e Sociedade, Campinas, v. 30, n. 108, p. 739-760, out. 2009.

PAIM, J. S. Reforma sanitária brasileira: contribuição para a compreensão e crítica. 2007. 300 p. Tese (Doutorado em Saúde Coletiva) - Universidade Federal da Bahia, Salvador, 2007.

PAVIANI, J. O professor na sala de aula. In: RAMOS, F. B.; PAVIANI, J. (org.). 0 professor, a escola e a educação. Caxias do Sul: EDUCS, 2009.

PIMENTA, S. G. Professor: formação, identidade e trabalho docente. In: PIMENTA, S. G. (Org.). Saberes pedagógicos e atividade docente. São Paulo: Cortez, 1999.

PORLÁN, A. R.; RIVERO, G. A. El conocimiento de los profesores. Sevilla: Díada, 1998. POZO, J. I.; CRESPO, M. A. G. A aprendizagem e o ensino de ciências: do conhecimento cotidiano ao conhecimento científico. Porto Alegre: Artmed, 2009.

PRIGOGINE, I. Ciência, razão e paixão. São Paulo: Livraria da Física, 2009.

PRIGOGINE, I. O fim da certeza. In: MENDES, C.; LARRETA, E. (org.). Representação e complexidade. Rio de Janeiro: Garamond, 2003.

REIS, D. C. Educação em saúde: aspectos históricos e conceituais. In: GAZZINELLI, M. F.; REIS, C. R.; MARQUES, R. C. (org.). Educação em saúde: teoria, método e imaginação. Belo Horizonte: UFMG, 2006.

RIBEIRO, K. G. et al. Educação e saúde em uma região em situação de vulnerabilidade social: avanços e desafios para as políticas públicas. Interface, Botucatu, v. 22, n. 1, p. 1387-1398, jun. 2018. 
ROCHA, D. S.; ADORNO, R. C. F. Abandono ou descontinuidade do tratamento da tuberculose em Rio Branco, Acre. Saúde e Sociedade, São Paulo, v. 21, n. 1, p. 232245, 2012.

ROCHA, H. H. P. Educação escolar e higienização da infância. Cadernos Cedes, Campinas, v. 23, n. 59, p. 39-56, abr. 2003.

RODRIGUES, J. C. Os corpos na antropologia. In: MINAYO, M. C. S.; COIMBRA JR, C. E. A. (org.). Críticas e atuantes: ciências sociais e humanas na saúde na América Latina. Rio de Janeiro: FIOCRUZ, 2005.

ROLDÃO, M. C. A mudança anunciada da escola ou um paradigma de escola em ruptura?. In: ALARCÃO, I. Escola reflexiva e nova racionalidade. Porto Alegre: Artme, 2001.

ROTHER, E. T. Revisão sistemática x revisão narrativa. Revista Acta Paulista de Enfermagem, São Paulo, v. 20, n. 2, abr./jun. 2007.

SACRISTAN, J. G. O currículo: uma reflexão sobre a prática. Porto Alegre: Artmed, 2000.

SANTOS, F. M.; EL-HANI, C. N. Belief, knowledge and understanding: how to deal with the relations between diferente cultural perspectives in classrooms. Science \& Education, v. 26, n. 15, p. 215-245, 2017.

SAVIANI, D. Escola e democracia. 42. ed. Campinas: Autores Associados, 2012.

SAVIANI, D. Escola e democracia. Campinas: Autores Associados, 2008.

SAVIANI, D. Pedagogia histórico-crítica: primeiras aproximações. Campinas: Autores Associados, 2011.

SCLIAR, M. História do conceito de saúde. Physis, Rio de Janeiro, v. 17, n. 1, p. 29-41, 2007.

SHIO, S. M. Educação e retórica na concepção de Hannah Arendt. In: RAMOS, F. B.; PAVIANI, J. (org.). O professor, a escola e a educação. Caxias do Sul: EDUCS, 2009.

SILVA, C. M. C.; MENEGHIM, M. C.; PEREIRA, A. C.; MIALHE, F. L. Educação em saúde: uma reflexão histórica de suas práticas. Ciência e Saúde Coletiva, Rio de Janeiro, v. 15, n. 5, p. 2539-2550, 2010. 
SILVA, M. A. Intervenção e consentimento: a política educacional do Banco Mundial. Campinas: FAPESP/Autores Associados, 2002.

STRECK, D. R. Qual o conhecimento que importa: desafios para o currículo. Currículo sem Fronteiras, v. 12, n. 13, p. 8-24, set./dez. 2012.

TARDIF, M. Elementos para uma epistemologia da prática profissional dos professores e suas consequências em relação à formação do magistério. Rio de Janeiro: Universidade de Laval/PUC-Rio, 2000.

TOZONI-REIS, M. F. C. A contribuição da sociologia da educação para a compreensão da educação escolar. Acervo Digital UNESP, 2010. Disponível em: https://acervodigital.unesp.br/bitstream/123456789/169/3/01d09t03.pdf. Acesso em: 12 nov. 2017.

TOZONI-REIS, M. F. C. Temas ambientais como "temas geradores": contribuições para uma metodologia educativa ambiental crítica, transformadora e emancipatória.

Educar, Curitiba, v. 22, n. 27, p. 93-110, 2006.

VALE, C. A.; JUNIOR, V. S.; PREZOTO, F. Febre Amarela: o mosquito, o macaco e o ser humano. Ces Revista, Juiz de Fora, v. 32, n. 2, p. 1-12, ago. 2018.

VALLE, D.; PIMENTA, D. N.; AGUIAR, R. Zika, dengue e chikungunya: desafios e questões. Epidemiologia e Serviços de Saúde, Brasília, v. 25, n. 2, abr./jun. 2016.

Enviado em: 19/05/2019

Aprovado em: 20/10/2020 